\title{
The Successful Management of a Patient With Exacerbation of Non-Cystic Fibrosis Bronchiectasis and Bilateral Fibrothorax Using a Venovenous Extracorporeal Carbon Dioxide Removal System
}

\author{
Giovanna Arcaro MD and Andrea Vianello MD
}

\begin{abstract}
Following unsuccessful treatment with noninvasive ventilation (NIV), patients requiring subsequent placement on invasive mechanical ventilation have a high mortality rate. Invasive mechanical ventilation is particularly problematic in patients with acute respiratory failure due to bronchiectasis exacerbation, as it is associated with a mortality rate of $19-35 \%$ and prolonged ICU stay. Here, we describe the successful management of a patient with exacerbated non-cystic fibrosis bronchiectasis using a pump-assisted venovenous system for extracorporeal $\mathrm{CO}_{2}$ removal (ProLUNG system) as an alternative to endotracheal intubation following NIV failure. The extracorporeal $\mathrm{CO}_{2}$ removal system proved to be safe and efficacious in this case study, and further studies focusing on its use in these types of cases seem warranted. Key words: bronchiectasis; extracorporeal $\mathrm{CO}_{2} \mathrm{re}$ moval; noninvasive ventilation. [Respir Care 2014;59(12):e197-e200. (C) 2014 Daedalus Enterprises]
\end{abstract}

\section{Introduction}

Although the efficacy of noninvasive ventilation (NIV) in reducing the need for endotracheal intubation and mortality has been clearly established, its failure rate remains high, exceeding $20 \%$ in patients without COPD..$^{1,2} \mathrm{~A}$ high mortality rate has been recently reported in a large group of patients who, following unsuccessful treatment with NIV, required subsequent application of invasive mechanical ventilation. ${ }^{2}$

Non-cystic fibrosis bronchiectasis is a progressive condition generally associated with chronic bacterial infections and characterized by irreversible destruction and dilation of the airways. ${ }^{3}$ The clinical course of individuals with non-cystic fibrosis bronchiectasis is variable, with a significant proportion of patients developing transient exacerbation leading to severe acute respiratory failure (ARF) and requiring ventilatory support. ${ }^{4}$ Although the use of

The authors are affiliated with the Respiratory Intensive Care Unit, City Hospital of Padova, Padova, Italy.

The authors have disclosed no conflicts of interest.

Correspondence: Andrea Vianello MD, Unità Operativa Fisiopatologia Respiratoria, Azienda Ospedaliera di Padova, Via Giustiniani 1, 35128 Padova, Italy. E-mail: avianello@qubisoft.it.

DOI: $10.4187 /$ respcare. 03184
NIV in bronchiectasis exacerbations may appear attractive as it can reduce ICU stay, its failure rate exceeds $25 \% .{ }^{5}$ At the same time, subsequent application of invasive mechanical ventilation, which is associated with a mortality rate of $19-35 \%$ and prolonged ICU stay, appears problematic. ${ }^{6}$

According to the National Institute for Health and Care Excellence guidance document issued in June 2012, ${ }^{7}$ extracorporeal $\mathrm{CO}_{2}$ removal should be used to remove $\mathrm{CO}_{2}$ from the blood of patients receiving mechanical ventilation who are unable to achieve adequate gas exchange at maximal tolerable ventilation pressures. Sporadic case reports and short case series concerning the use of an extracorporeal $\mathrm{CO}_{2}$ removal system in patients who develop severe acute hypercapnic respiratory failure of various etiologies but do not respond adequately to NIV have been published in recent years. Extracorporeal $\mathrm{CO}_{2}$ removal has, in fact, been successfully employed, and intubation has been avoided in some cases of exacerbation of COPD, ${ }^{8-12}$ cystic fibrosis, pulmonary fibrosis, severe asthma, ${ }^{8}$ and bronchiolitis obliterans. ${ }^{13}$

Despite increasing interest in the use of extracorporeal $\mathrm{CO}_{2}$ removal systems in patients who develop refractory hypercapnic ARF, its utility in the event of exacerbations in non-cystic fibrosis bronchiectasis has not been assessed. This report describes the management of a patient with exacerbated bilateral bronchiectasis, fibrothorax, and hypercapnic respiratory failure who was successfully treated 
by extracorporeal $\mathrm{CO}_{2}$ removal following ineffective NIV support.

\section{Case Report}

A 36-y-old male patient was admitted to the respiratory ICU of the City Hospital of Padova, Italy, for ARF. With a known case of severe bilateral bronchiectasis, bullous emphysema, and bilateral fibrothorax diagnosed at the age of $27 \mathrm{y}$, the patient presented with a history of increasing productive cough and breathing difficulty over the preceding week's time, accompanied by orthopnea, hypersomnolence, asthenia, and palpitations. The patient also reported suffering from recurrent lower respiratory tract infections over the preceding $3 \mathrm{y}$. Besides his regular therapy, he was receiving long-term oxygen therapy with nocturnal NIV. Three months before admission to the hospital, the patient was placed on a waiting list for bilateral lung transplantation with a normal priority status because of increasing deterioration of ventilatory function, a vital capacity of $25 \%$ predicted $(1.33 \mathrm{~L})$.

At admission, the patient was moderately agitated, tachycardic, polypneic, and fatigued. Physical examination revealed pulmonary cachexia and tachypnea (breathing frequency of 30 breaths/min), cyanosis, weak cough with purulent sputum, and diffuse subcrepitant bilateral rales. He was severely hypoxic and hypercapnic breathing room air, and arterial blood gas values were $\mathrm{pH} 7.36, \mathrm{P}_{\mathrm{aCO}_{2}}$ of $68 \mathrm{~mm} \mathrm{Hg}, \mathrm{P}_{\mathrm{aO}_{2}}$ of $50 \mathrm{~mm} \mathrm{Hg}$, and $\mathrm{HCO}_{3}{ }^{-}$of $38.1 \mathrm{mmol} / \mathrm{L}$. After supplemental oxygen was provided, $\mathrm{CO}_{2}$ retention further increased $\left(\mathrm{pH} 7.30, \mathrm{P}_{\mathrm{aCO}_{2}}\right.$ of $89 \mathrm{~mm} \mathrm{Hg}, \mathrm{P}_{\mathrm{aO}_{2}}$ of $60 \mathrm{~mm} \mathrm{Hg}, \mathrm{HCO}_{3}{ }^{-}$of $43.4 \mathrm{mmol} / \mathrm{L}$, and $\mathrm{P}_{\mathrm{aO}_{2}} / \mathrm{F}_{\mathrm{IO}_{2}}$ of 201 ). Complete hematological workup revealed moderate anemia (hemoglobin, $8.7 \mathrm{~g} / \mathrm{L}$ ) and leukocytosis (white blood cells, $13,600 \times 10^{6}$ cells/L); serum electrolytes were normal. A chest X-ray showed bilateral thick parallel lines in the lower lobes, emphysematous bullae of the right and left upper lobes, bilateral pleural thickening, and a small calcification. The patient was treated with intravenous piperacillin, levofloxacin, and diuretics.

As ventilatory assistance was needed, NIV was initiated using a portable ventilator (Elisée 150, ResMed San Diego, California) set on the pressure support ventilation mode. Pressure support ventilation was initially titrated to a moderate tidal volume $(6-8 \mathrm{~mL} / \mathrm{kg})$. The ventilatory setting was then readjusted according to arterial blood gas values; our goals were to maintain arterial oxygen saturation $\left(\mathrm{S}_{\mathrm{aO}_{2}}\right)$ at $>90 \%, \mathrm{P}_{\mathrm{aCO}}$ at $<50 \mathrm{~mm} \mathrm{Hg}$, and to reduce the breathing frequency. The initial pressure support level did not exceed $25 \mathrm{~cm} \mathrm{H}_{2} \mathrm{O}$ and was progressively elevated by $1-2 \quad \mathrm{~cm} \mathrm{H}_{2} \mathrm{O}$ without exceeding $40 \mathrm{~cm} \mathrm{H}_{2} \mathrm{O}$ due to the high risk of pneumothorax (maximal pressure support, $25.8 \pm 2.6 \mathrm{~cm} \mathrm{H}_{2} \mathrm{O}$ ). PEEP was set at $5 \mathrm{~cm} \mathrm{H}_{2} \mathrm{O}$ to obtain the best oxygenation with minimal hemodynamic side effects, and the levels were raised by 1-2 $\mathrm{cm} \mathrm{H}_{2} \mathrm{O}$ without exceeding 6-8 $\mathrm{cm} \mathrm{H}_{2} \mathrm{O}$ (maximal PEEP, $5.1 \pm 1.7 \mathrm{~cm} \mathrm{H}_{2} \mathrm{O}$ ). Supplemental oxygen was added to the ventilator circuit. The patient was connected to the ventilator by a full face mask; colloid dressings were placed on the major pressure points to minimize skin injury. NIV was delivered continuously except for brief rest periods (30-60 $\mathrm{min}$ ) to allow the patient to receive dietary liquid supplements and to speak. A standard ICU monitoring system displaying electrocardiogram, pulse oximetry, invasive blood pressure, and breathing frequency measurements was utilized.

Despite continuous use of NIV, pulmonary gas exchange progressively deteriorated: on day 3 after admission, arterial blood gas levels resulted in increasingly severe hypoxia and hypercapnia $\left(\mathrm{pH} 7.29, \mathrm{P}_{\mathrm{CO}_{2}}\right.$ of $89 \mathrm{~mm} \mathrm{Hg}$, and $\mathrm{P}_{\mathrm{aO}_{2}}$ of $59 \mathrm{~mm} \mathrm{Hg}$ during assist ventilation). The patient also showed signs of exhaustion (breathing frequency of $30-40$ breaths $/ \mathrm{min}$ ), increasing intolerance to uninterrupted NIV, and an imminent need for invasive mechanical ventilation. In view of the high risk of complications linked to invasive ventilation, we informed the patient about an alternative venovenous extracorporeal $\mathrm{CO}_{2}$ removal method available in our hospital that had already been approved for an investigational feasibility study by our local ethics committee. He was also provided detailed information about the benefits and risks of that system.

The extracorporeal $\mathrm{CO}_{2}$ removal device used in our center is the ProLUNG system (Estor, Milan, Italy), a pump-driven venovenous system that utilizes a small single venovenous dual-lumen catheter (13 French) that can be inserted into a femoral or jugular vein. It is characterized by a low blood flow (up to a maximum of $450 \mathrm{~mL} / \mathrm{min}$ ) and a single-use-only gas exchange cartridge consisting of a hollow fiber polypropylene diffusion membrane network with an effective surface area of $1.35 \mathrm{~m}^{2}$. As the device uses a total volume circuit of only $120 \mathrm{~mL}$, the hemodynamic impact on the patient is minimized. Oxygen flows as a carrier gas within the hollow fibers, and $\mathrm{CO}_{2}$ moves by selective diffusion across the concentration gradient from the blood.

The patient gave his consent to treatment with this device. While the patient was supine, a 13 French catheter was inserted percutaneously without complication via the right femoral vein and connected to the extracorporeal circuit. Blood flow was initiated through the circuit by a centrifugal pump at $300 \mathrm{~mL} / \mathrm{min}$. Oxygen flow through the gas exchanger was initiated at $12 \mathrm{~L} / \mathrm{min}$ to maximize $\mathrm{CO}_{2}$ removal. In accordance with study protocol guidelines for anticoagulation, the patient was started on an intravenous heparin infusion to maintain an activated clotting time of $150-180 \mathrm{~s})$.

The amount of $\mathrm{CO}_{2}$ removed by the device was adjusted depending on the arterial blood gas and breathing fre- 
Non-CF Bronchiectasis and Venovenous Extracorporeal $\mathrm{CO}_{2}$ Removal
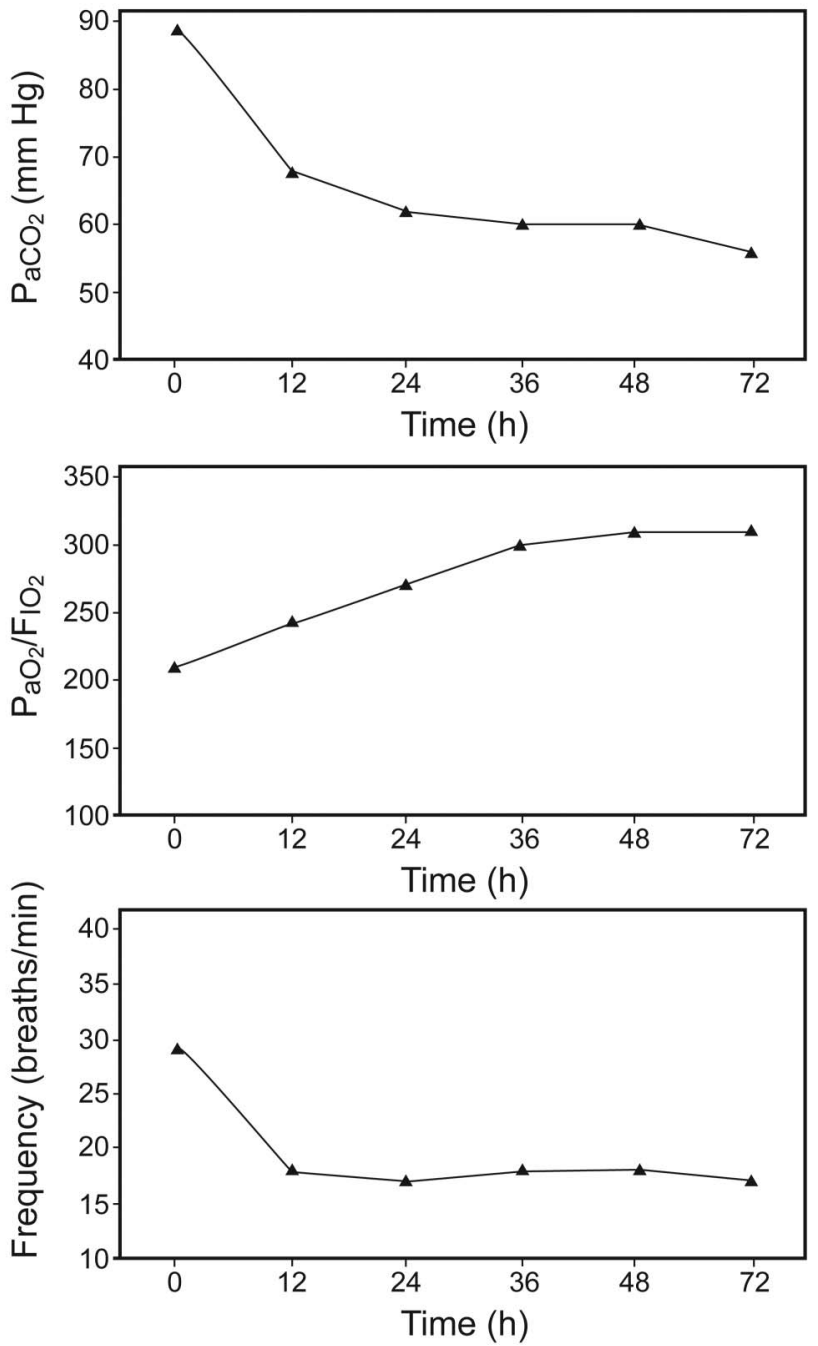

Fig. 1. Changes in $\mathrm{P}_{\mathrm{acO}}, \mathrm{P}_{\mathrm{aO}} / \mathrm{F}_{1 \mathrm{O}_{2}}$, and breathing frequency after extracorporeal $\mathrm{CO}_{2}$ removal was initiated.

quency levels, which were measured every $4 \mathrm{~h}$. During application, the ProLUNG circuit blood flow varied from 300 to $450 \mathrm{~mL} / \mathrm{min}$; the remainder of gas exchange occurred through the lungs using NIV adjusted to releasing low tidal volume $(6-8 \mathrm{~mL} / \mathrm{kg})$ with a low/moderate PEEP level.

$\mathrm{P}_{\mathrm{aCO}}$ decreased after extracorporeal $\mathrm{CO}_{2}$ removal therapy was initiated from $89 \mathrm{~mm} \mathrm{Hg}$ before cannulation to $59 \mathrm{~mm} \mathrm{Hg}$ within $24 \mathrm{~h}$; the patient's breathing frequency also decreased from 30 to $16-18$ breaths $/ \mathrm{min}$. $\mathrm{P}_{\mathrm{aCO}_{2}}$ subsequently remained within a range of $60-54 \mathrm{~mm} \mathrm{Hg}$ for the duration of therapy (Fig. 1). The patient's clinical status progressively improved over the next $5 \mathrm{~d}$, permitting a reduction in NIV application from continuous use, except for brief rest periods, to 5-6 $\mathrm{h}$ off the ventilator by day 3 . By day 4, the patient was able to breathe without ventilatory support for 10 consecutive $h$. On day 5 , the patient was increasingly active and clinically stable, and extracor- poreal support was suspended. The catheter was removed, coagulation values were normal, and there was no additional bleeding. The patient was subsequently supported with nighttime NIV. There were no other complications during or after extracorporeal $\mathrm{CO}_{2}$ removal. On day 7 , the patient was transferred to the pulmonary division in good clinical condition. He was mildly hypercapnic during supplemental oxygen therapy, and the arterial blood gas values were $\mathrm{pH} 7.40, \mathrm{P}_{\mathrm{aCO}_{2}} 54.3 \mathrm{~mm} \mathrm{Hg}, \mathrm{P}_{\mathrm{aO}_{2}} 87 \mathrm{~mm} \mathrm{Hg}$, $\mathrm{HCO}_{3}{ }^{-} 34 \mathrm{mmol} / \mathrm{L}$, and $\mathrm{P}_{\mathrm{aO}} / \mathrm{F}_{\mathrm{IO}}, 310.7$. He was subsequently discharged from the hospital on home nighttime ventilation via nasal mask.

\section{Discussion}

Some individuals with bronchiectasis require intensive care therapy and ventilatory support for ARF: in that event, noninvasive ventilatory management can become problematic due to severe blood gas derangement, partially ineffective cough, and airway mucus encumbrance, which can lead to the need for endotracheal intubation. A substantial proportion of patients with bronchiectasis fail to be weaned from invasive mechanical ventilation due to inadequate cough, generalized weakness, and/or hemodynamic instability, which is possibly the outcome of cor pulmonale, and they should be considered at high risk for complications such as development of ventilator-associated pneumonia or ventilator-induced lung injury, severe sepsis, and multi-organ failure syndrome. ${ }^{6,14}$

There are no studies to date concerning utilization of extracorporeal $\mathrm{CO}_{2}$ removal devices as an alternative to endotracheal intubation to treat patients with bronchiectasis exacerbation suffering from ARF in whom NIV treatment is ineffective. The findings from the case report outlined here suggest that the timely use of an extracorporeal $\mathrm{CO}_{2}$ removal system in addition to NIV can prevent or reduce the need for endotracheal intubation and avoid potential problems linked to the application of invasive mechanical ventilation. The probability of weaning failure was particularly high in the patient described here due to coexisting fibrothorax, which may have impaired respiratory mechanics and further increased the work of breathing. 15

Although extracorporeal support devices present potential complications, including vessel perforation, bleeding, and infections, ${ }^{16}$ in our case, those drawbacks were minimized by using venovenous cannulation as opposed to the traditional veno-arterial cannulation and by reducing the catheter size. Smaller catheters reduce circuit blood flows and hence the amount of $\mathrm{CO}_{2}$ removal. In the case studied, the level of gas exchange was nevertheless satisfactory in terms of improved arterial blood gas levels. Within $24 \mathrm{~h}$, in fact, there was a relevant reduction in hypercapnia, with 


\section{Non-CF Bronchiectasis and Venovenous Extracorporeal $\mathrm{CO}_{2}$ Removal}

a $30 \mathrm{~mm} \mathrm{Hg}$ fall in $\mathrm{P}_{\mathrm{aCO}}$, and the mean arterial $\mathrm{pH}$ reached $\sim 7.40$.

Finally, as the device did not require specialized staff/ training and proved simple to use, it is presumable that it could be safely implemented in any medical or surgical ICU.

To summarize, the satisfactory outcome of this case confirms the importance of designing other studies to assess the use of venovenous extracorporeal $\mathrm{CO}_{2}$ removal systems in patients with exacerbated bronchiectasis and severe respiratory failure in whom NIV alone is ineffective.

\section{REFERENCES}

1. Hill NS, Brennan J, Garpestad E, Nava S. Noninvasive ventilation in acute respiratory failure. Crit Care Med 2007;35(10):2402-2407.

2. Walkey AJ, Wiener RS. Use of noninvasive ventilation in patients with acute respiratory failure, 2000-2009: a population-based study. Ann Am Thorac Soc 2013;10(1):10-17.

3. O'Donnell AE. Bronchiectasis. Chest, 2008;134(4):815-823.

4. Loebinger MR, Wells AU, Hansell DM, Chinyanganya N, Devaraj A, Meister M, Wilson R. Mortality in bronchiectasis: a long-term study assessing the factors influencing survival. Eur Respir J 2009; 34(4):843-849.

5. Dupont M, Gacouin A, Lena H, Lavoué S, Brinchault G, Delaval P, Thomas R. Survival of patients with bronchiectasis after the first ICU stay for respiratory failure. Chest 2004;125(5):1815-1820.

6. Phua J, Ang YL, See KC, Mukhopadhyay A, Santiago EA, Dela Pena EG, Lim TK. Noninvasive and invasive ventilation in acute respiratory failure associated with bronchiectasis. Intensive Care Med 2010;36(4):638-647.

7. National Institute for Health and Care Excellence. Extracorporeal membrane carbon dioxide removal. NICE interventional procedure guidance 428. Issued June 2012. http://guidance.nice.org.uk/ipg428. Accessed on June 2, 2014.

8. Kluge S, Braune SA, Engel M, Nierhaus A, Frings D, Ebelt H, et al. Avoiding invasive mechanical ventilation by extracorporeal carbon dioxide removal in patients failing noninvasive ventilation. Intensive Care Med 2012;38(10):1632-1639.

9. Bonin F, Sommerwerck U, Lund LW, Teschler H. Avoidance of intubation during acute exacerbation of chronic obstructive pulmonary disease for a lung transplant candidate using extracorporeal carbon dioxide removal with the Hemolung. J Thorac Cardiovasc Surg 2013;145(5):e43-e44.

10. Lund LW, Federspiel WJ. Removing extra $\mathrm{CO}_{2}$ in COPD patients. Curr Respir Care Rep 2013;2:131-138.

11. Mani RK, Schmidt W, Lund LW, Herth FJ. Respiratory dialysis for avoidance of intubation in acute exacerbation of COPD. ASAIO J 2013;59(6):675-678.

12. Burki NK, Mani RK, Herth FJ, Schmidt W, Teschler H, Bonin F, et al. A novel extracorporeal $\mathrm{CO}_{2}$ removal system: results of a pilot study of hypercapnic respiratory failure in patients with COPD. Chest 2013;143(3):678-686.

13. Moscatelli A, Ottonello G, Nahum L, Lampugnani E, Puncuh F, Simonini A, et al. Noninvasive ventilation and low-flow veno-venous extracorporeal carbon dioxide removal as a bridge to lung transplantation in a child with refractory hypercapnic respiratory failure due to bronchiolitis obliterans. Pediatr Crit Care Med 2010; 11(1):e8-e12.

14. Alzeer AH, Masood M, Basha SJ, Shaik SA. Survival of bronchiectatic patients with respiratory failure in ICU. BMC Pulm Med 2007;7:17.

15. Criner GJ, Brennan K, Travaline JM, Kreimer D. Efficacy and compliance with noninvasive positive pressure ventilation in patients with chronic respiratory failure. Chest 1999;116(3):667-675.

16. Bein T, Weber F, Philipp A, Prasser C, Pfeifer M, Schmid FX, et al A new pumpless extracorporeal interventional lung assist in critical hypoxemia/hypercapnia. Crit Care Med 2006;34(5):1372-1377. 